\title{
Commentary on "Improving the seasonal cycle and interannual variations of biomass burning aerosol sources" by Generoso et al.
}

\author{
L. Giglio and J. D. Kendall \\ Science Systems and Applications, Inc., NASA Goddard Space Flight Center, Code 923, Greenbelt, Maryland, USA
}

Received: 21 October 2003 - Published in Atmos. Chem. Phys. Discuss.: 27 November 2003

Revised: 24 February 2004 - Accepted: 31 March 2004 - Published: 13 April 2004

\begin{abstract}
In a recent published paper, Generoso et al. (2003) describe a method for improving the spatial and temporal distribution of pyrogenic aerosol emission inventories. In the course of their analysis, the authors note several significant discrepancies in the seasonality of burning as observed by the Visible and Infrared Scanner (VIRS) and four other biomass burning data sets derived from satellite observations. In this commentary we explain the source of these discrepancies and clarify the origin of the VIRS observations that were used by Generoso et al.
\end{abstract}

\section{Introduction}

In a recent published paper, Generoso et al. (2003) describe a method for improving the spatial and temporal distribution of pyrogenic aerosol emission inventories by redistributing independent aerosol emissions using fire counts derived from satellite observations. In the paper, the authors present results using "hot-spots" or fire counts derived from nighttime observations of the Along Track Scanning Radiometer (ATSR). However, they indicate that other remotely-sensed fire products could be used in a similar fashion because, on the whole, they exhibit a similar distribution and seasonality in biomass burning. The other satellite data sets cited include the World Fire Web Advanced Very High Resolution Radiometer (AVHRR) fire count, SPOT Vegetation burnt area (GBA2000), ATSR burnt area (GLOBSCAR), and Tropical Rainfall Measuring Mission (TRMM) Visible and Infrared Scanner (VIRS) fire count products.

The authors note, however, a significant discrepancy in the burning seasonality of the Sahel region in Africa as observed by the VIRS and the four other biomass burning data sets. In addition, Fig. 3 of their paper shows VIRS detecting an

Correspondence to: L. Giglio

(giglio@ hades.gsfc.nasa.gov) astonishing number of fires during the southern African wet season (December), in contrast to the four other data sets for the same time period. In this commentary we explain the source of these discrepancies and correct an error in the attribution of the VIRS fire product used by Generoso et al. (2003).

\section{Discussion}

Although Generoso et al. (2003) cite our VIRS fire product (Giglio et al., 2003, 2000) as the source of the VIRS data used in their study, they in fact used an independent VIRS fire product developed by Ji and Stocker (2002). The two products have some substantial differences. The total number of fire pixels detected worldwide each month, for example, typically differs by a factor of nearly four. More importantly, fire seasonality is markedly different in some regions, including west Africa, southern Africa, Southeast Asia, and Australia. This is illustrated in Fig. 1, which shows the 19982002 monthly average number of fire pixels recorded in both products for the Sahel and southern Africa regions as defined by Generoso et al. (2003). Glint-contaminated pixels were excluded from the Ji and Stocker product using the criteria they prescribe (Ji and Stocker, 2002).

Several features are evident from Fig. 1. First, a comparison with the time series in Fig. 3 of Generoso et al. (2003) shows our data set to be in good agreement with the AVHRR World Fire Web, ATSR, GBA2000, and GLOBSCAR products. Second, the numbers of fire pixels recorded by the two data sets differ by nearly an order of magnitude. Finally, the Ji and Stocker (2002) data set exhibits unusual seasonality in southern African and Sahelian fire activity. In the case of southern Africa, fire activity does not decrease with the onset of the wet season in November. In fact, the Ji and Stocker (2002) data set places the maximum fire activity in December, well within the southern African wet season and 

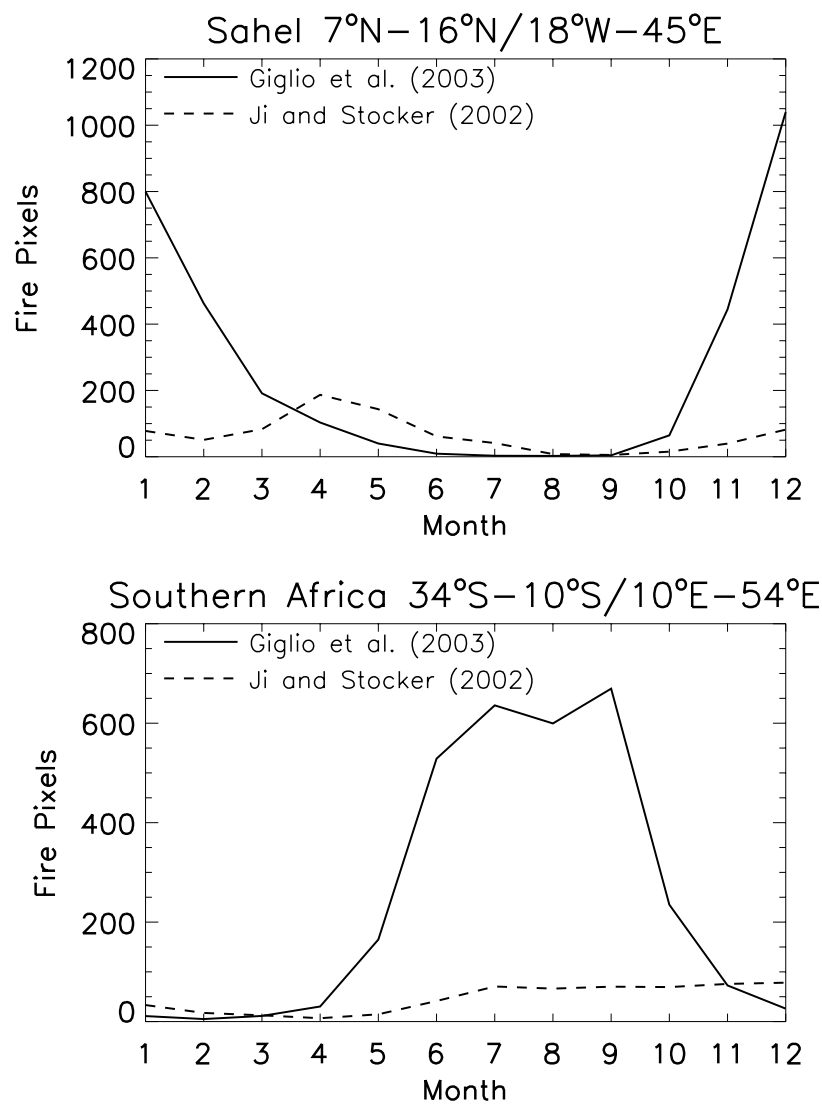

Fig. 1. 1998-2001 average number of fire pixels observed each month from the Giglio et al. (2003) and Ji and Stocker (2002) VIRS fire data sets in the Sahel and southern Africa. Note that the Ji and Stocker (2002) time series shown here are four-year monthly averages that consequently differ slightly from the year $2000 \mathrm{Ji}$ and Stocker time series shown in Fig. 3 of Generoso et al. (2003).

in contradiction to an extensive body of literature on biomass burning in Africa, e.g. Van Wilgen et al. (1990). In the case of the Sahel, the Ji and Stocker (2002) data set shows very little fire activity during the documented Sahelian fire season (approximately November through March), and maximum fire activity during April and May. Examination of VIRS imagery for these locations and time periods show that the unseasonal fires observed in the Ji and Stocker data set are, in fact, widespread false alarms along the edges of clouds and in areas of sun glint. We show an example of each in Figs. 2 and 3.

The smaller number of fire pixels shown in Fig. 1 for the Ji and Stocker (2002) data set is a consequence of the comparatively high ( $320 \mathrm{~K}$ day, $315 \mathrm{~K}$ night) minimum $3.75 \mu \mathrm{m}$ brightness temperatures Ji and Stocker require of fire pixels. Pixels containing smaller and/or cooler fires will frequently not exceed these thresholds.

With respect to the issue of clouds, Ji and Stocker (2002) employ a single threshold test to eliminate cloud contamina-

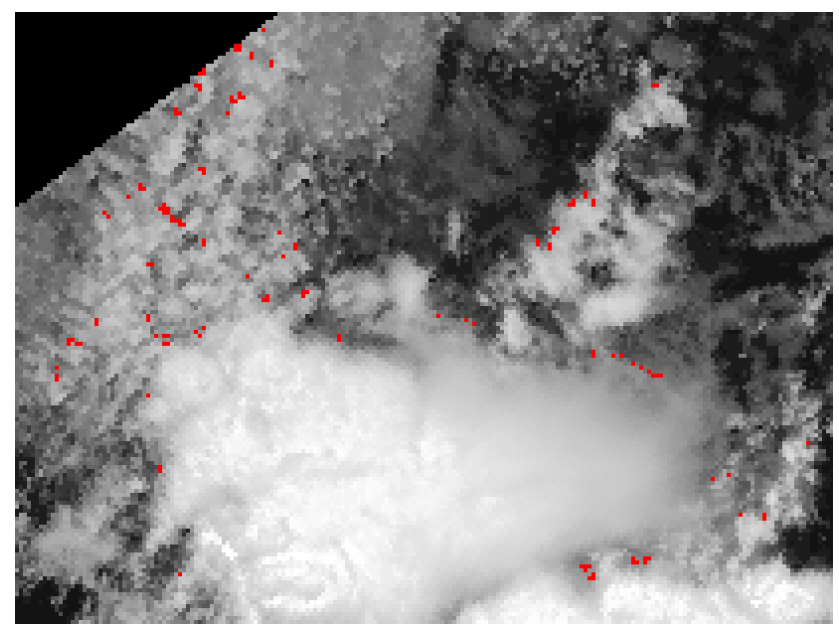

Fig. 2. Example of cloud-induced false fire pixels present in the Ji and Stocker (2002) VIRS fire product in Sudan (7 May 1998, 10:26 UTC). Fire pixels are shown in red, superimposed on a greyscale image of the VIRS $0.63 \mu \mathrm{m}$ channel reflectances. Note how false fire pixels (more than 50 in this scene) occur along edges of clouds. Image spans an area approximately $400 \mathrm{~km}$ by $300 \mathrm{~km}$ in size, with its center located at approximately $8.5^{\circ} \mathrm{N}, 28.5^{\circ} \mathrm{E}$. The black triangle in the upper left (northwest) corner of the image lies beyond the edge of the VIRS swath. The Giglio et al. (2003) VIRS fire product shows zero fire pixels for this scene.

tion: the $10.8 \mu \mathrm{m}$ brightness temperature must exceed $285 \mathrm{~K}$. Previous work, however, has shown that such an approach is problematic over land (Saunders and Kriebel, 1988). Furthermore, even with good cloud masking, cloud edges remain ambiguous and are generally a source of false alarms for operational fire detection (Giglio et al., 1999; Seielstad et al., 2002). For this reason, we include a test specifically for rejecting such false alarms in our detection algorithm (Giglio et al., 2003).

In the case of sun glint, our experience suggests that the glint-rejection tests of the type prescribed by Ji and Stocker (2002) (reject all fire pixels having a $0.63 \mu \mathrm{m}$ reflectance above 0.3 ) are inadequate for an operational fire product, particularly for a non-sun-synchronous platform such as TRMM. Fixed glint thresholds are simply too inflexible to be applied globally. The 22 false fire pixels in Fig. 3, for example, have $0.63 \mu \mathrm{m}$ reflectances between 0.15 and 0.30 , with a mean of 0.21 . Reflectances in this range are typical in the absence of glint for many regions. For this reason, we use a three-tiered approach involving the sun and satellite geometry, $1.6 \mu \mathrm{m}$ reflectance, and proximity to water bodies (Giglio et al., 2003). This restricts our threshold tests to only those sun and satellite configurations for which glint is much more likely to occur. 


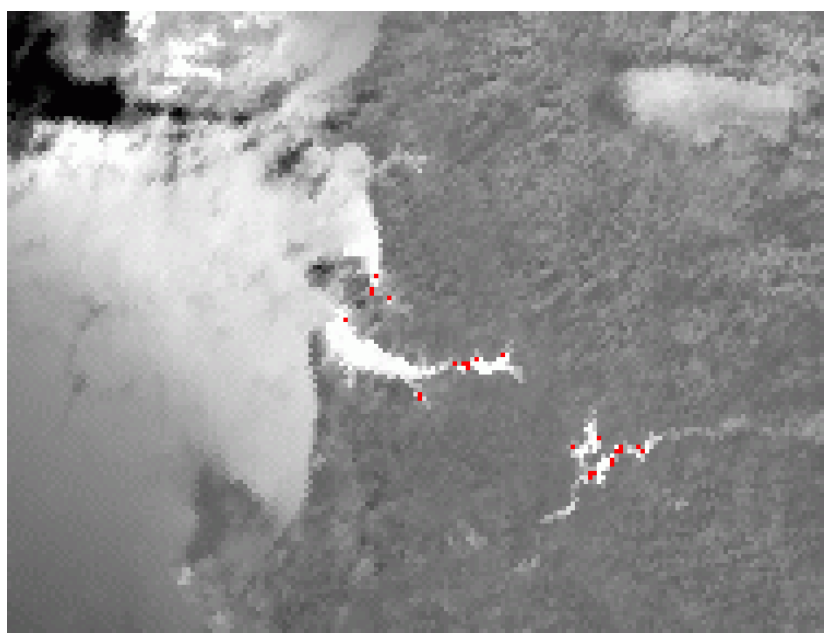

Fig. 3. Example of false fire pixels caused by sun glint in the Ji and Stocker (2002) VIRS fire product in Gabon (1 February 2002, 12:16 UTC). Fire pixels are shown in red, superimposed on a grey-scale image of the VIRS $3.75 \mu$ m channel brightness temperature. False fire pixels occur near Libreville and along the Ogooué and Okano rivers. Image spans an area approximately $400 \mathrm{~km}$ by $300 \mathrm{~km}$ in size, with its center located at approximately $0^{\circ} \mathrm{N}, 10^{\circ} \mathrm{E}$. The Giglio et al. (2003) VIRS fire product shows zero fire pixels for this scene. The dark blob in the upper left (northwest) corner of the image is a large cloud.

\section{Conclusions}

The VIRS fire data set used by Generoso et al. (2003) was not the Giglio et al. (2003) VIRS fire product as cited, but rather an independent VIRS fire product developed by Ji and Stocker (2002). The unusual behavior of this alternate VIRS fire product observed by Generoso et al. (2003) is due to a high rate of false alarms that is inherent in the methodology used by Ji and Stocker (2002) rather than deficiencies in the VIRS sensor. In closing, we note that any data set derived from remotely sensed data, including our own VIRS fire product, is subject to errors. We believe that it is the responsibility of data providers to document errors and other limitations and make this information readily available to assist end-users in understanding how their data sets can be used appropriately.

\section{Appendix: Data set distribution}

The Giglio et al. (2003) VIRS monthly fire product and documentation is available from the Goddard Distributed Active Archive Center (DAAC) (http://daac.gsfc. nasa.gov/hydrology/TRMM_VIRS_Fire.shtml). The Ji and Stocker (2002) VIRS monthly fire product is available from the TRMM Science Data and Information System (ftp:// ftp-tsdis.gsfc.nasa.gov/pub/yji/MONTHLY/).

\section{References}

Generoso, S., Bréon, F.-M., Balkanski, Y., Boucher, O., and Schulz, M.: Improving the seasonal cycle and interannual variations of biomass burning aerosol sources, Atmos. Chem. Phys., 3, 12111222, 2003.

Giglio, L., Kendall, J. D., and Justice, C. O.: Evaluation of global fire detection algorithms using simulated AVHRR infrared data, Int. J. Remote Sensing, 20, 1947-1985, 1999.

Giglio, L., Kendall, J. D., and Mack, R.: A multi-year active fire data set for the tropics derived from the TRMM VIRS, Int. J. Remote Sensing, 24, 4505-4525, 2003.

Giglio, L., Kendall, J. D., and Tucker, C. J.: Remote sensing of fires with the TRMM VIRS, Int. J. Remote Sensing, 21, 203-207, 2000.

Ji, Y. and Stocker, E.: An overview of the TRMM/TSDIS fire algorithm and product, Int. J. Remote Sensing, 23, 3285-3303, 2002.

Saunders, R. W. and Kriebel, K. T.: An improved method for detecting clear-sky and cloud radiances from AVHRR data, Int. J. Remote Sensing, 9, 123-150, 1988.

Seielstad, C. A., Riddering, J. P., Brown, S. R., Queen, L. P., and Hao, W. M.: Testing the sensitivity of a MODIS-like daytime active fire detection model in Alaska using NOAA/AVHRR infrared data, Phot. Eng. and Remote Sensing, 68, 831-838, 2002.

Van Wilgen, B. W., Everson, C. S., and Trollope, W. S. W.: Fire management in southern Africa: some examples of current objectives, practices, and problems, in: Fire in the Tropical Biota: Ecosystem Processes and Global Challenges, edited by Goldammer, J. G., Berlin: Springer-Verlag, 1990. 